\title{
STRUCTURE AND PROPERTIES OF N,N-DI-n-BUTYLDITHIOCARBAMATO-1, 2-DICYANOETHENE-1, 2-DITHIOLATO-GOLD(III)
}

\author{
J. H. NOORDIK, Th. W. HUMMELINK and J. G. M. VAN DER LINDEN
}

Department of Inorganic Chemistry and Crystallography, University of Nijmegen, Nijmegen, The Netherlands

(Received February 24, 1972; in final form July 25, 1972)

\begin{abstract}
The crystal and molecular structure and some spectral data of the compound N,N-di-n-butyldithiocarbamato-1, 2-dicyanoethene-1, 2-dithiolato-gold(II), $\mathrm{AuS}_{2} \mathrm{CN}\left(\mathrm{C}_{4} \mathrm{H}_{9}\right)_{2} \mathrm{~S}_{2} \mathrm{C}_{2}(\mathrm{CN})_{2}$, are reported. The crystal structure has been determined from a three-dimensional single-crystal X-ray diffraction study. The orthorombic cell, space group Pbca, with $a=14.066(3), b=28.980(2)$ and $c=9.192(2) \AA$, contains eight formula units. Intensity data were collected on an automatic diffractometer. The structural parameters were refined by full-matrix least-squares methods to a conventional $R$-factor of 0.047 for 1587 independent non-zero reflections. The structure determination proved the compound to be a mixed dithiocarbamato-dithiolato complex, Au(dtc)(mnt), (dtc = N,N-di-n-butyldithiocarbamate, $\mathrm{mnt}=$ maleonitriledithiolate $\equiv 1$, 2-dicyanoethene-1, 2-dithiolate), as expected from spectral data. The gold atom is in approximately square-planar coordination, however, deviations from $\mathrm{mm} 2\left(\mathrm{C}_{2 v}\right)$ symmetry are considerable. Au-S bond distances in the dtc-moiety $(2.329(5) \AA$ and $2.324(5) \AA)$ are significantly longer than those in the mnt-moiety $(2.303(5) \AA$ and $2.284(5) \AA)$. The molecules are packed pairwise around inversion centres with relatively short intermolecular S-S distances.
\end{abstract}

\section{INTRODUCTION}

Recently the structure of the ionic compound $\mathrm{Au}(\mathrm{dtc})_{2}+\mathrm{Au}(\mathrm{mnt})_{2}{ }^{-},(\mathrm{dtc}=N, N$-di-n-butyldithiocarbamate, $\mathrm{mnt}=$ maleonitriledithiolate $\equiv 1,2$-dicyanoethene-1,2-dithiolate) has been reported. ${ }^{1}$ In the present paper we report the crystal structure and some spectral data of the isomeric mixed-ligand complex $\mathrm{Au}(\mathrm{dtc})(\mathrm{mnt})$. This complex belongs to a cl of complexes of the type $M\left(R_{2} \mathrm{dtc}\right)(\mathrm{mnt})^{z}$, $(z=0, M=\mathrm{Ni}, \mathrm{Cu}, \mathrm{Au}: z=-1, M=\mathrm{Ni}, \mathrm{Cu}$, Pd, Pt: $\quad R_{2} \mathrm{dtc}=N, N$-di-alkyldithiocarbamate $=$ $R_{2} \mathrm{NCS}_{2}{ }^{-}$) of which the given members have ' recently been synthesized and characterized. ${ }^{2,}{ }^{3}$ The structure determination presents the first X-ray analysis of a bis-complex involving both a 1,1- and a 1,2-dithiolato ligand. ${ }^{4}$

\section{EXPERIMENTAL}

\section{$X$-ray Crystal Structure Analysis}

The compound $\mathrm{Au}(\mathrm{dtc})(\mathrm{mnt})$ was prepared as reported previously, ${ }^{3}$ and crystallizes as wellformed green plate-shaped crystals. Preliminary oscillation, rotation and Weissenberg photographs taken with $\mathrm{Cu} K \alpha$ radiation showed that the crystals belonged to the orthorhombic system. The systematic absences were found to be $h 0 l$ absent for $l=2 n+1 ; 0 k l$ absent for $k=2 \mathrm{n}+1 ; h k 0$ absent for $h=2 n+1$; space group Pbca. The unit cell dimensions were obtained from Pt-calibrated Weissenberg photographs. Least-squares adjustment of observed $\Theta$-values for $146 h k 0$ and $84 \mathrm{~h} 0 \mathrm{l}$ reflections $\left(56^{\circ}<\Theta<81^{\circ}\right)$ resulted in $a=14.066(3) \AA, b=28.980(2) \AA, c=9.192(2) \AA$ and $V_{c}=3747(1) \AA^{3}$.

The calculated density of $1.92 \mathrm{~g} \mathrm{~cm}^{-3}$ for F.W. $=541.52$ and $Z=8$, agrees well with the value of $1.93(1) \mathrm{g} \mathrm{cm}^{-3}$ measured by flotation in a tetrachloromethane/iodomethane mixture. Intensity data were collected on an automatic diffractometer using the moving-counter moving-crystal method. Three series of intensity data were collected for a crystal of approximate dimensions $0.20 \times 0.08 \times$ $0.30 \mathrm{~mm}^{3}$ that was mounted with $c$ along the $\phi$-axis.

I. The octant $h k l$ (all indices positive), scan speed $0.3^{\circ} / \mathrm{min}$.

I. The octant $h k l$ (all indices positive), scan speed $1.2^{\circ} / \mathrm{min}$.

III. The octant $h k l$ ( $h$ and $k$ indices negative, $l$ index positive), scan speed $0.3^{\circ} / \mathrm{min}$. 
For each of the series of measurements reciprocal space was explored up to $\sin \Theta / \lambda=0.60 \AA^{-1}$ using Zr-filtered Mo-radiation $(\lambda=0.71069 \AA$, linear absorption coefficient $\mu=85.6 \mathrm{~cm}^{-1}$ ). After every fifteen reflections a reference reflection was measured to detect and allow corrections to be made for slow fluctuations in the primary beam. (Differences between the intensities of the reference reflections did not exceed $3 \%$ ). The intensity data were corrected in the usual way for Lorentz and polarization effects and absorption. The latter correction was calculated according to the Busing and Levy ${ }^{5}$ scheme: $11 \times 4 \times 13$ volume elements and 16 accurately located boundary planes were taken into account. (The maximum and minimum values of the absorption factor in the intensities are 4.55 and 1.83 respectively). After absorption correction the three series of intensity data were brought to a common scale.

Comparison of the three series of intensity data resulted in $R_{\mathrm{I}, \mathrm{II}}=0.040, R_{\mathrm{I}, \mathrm{III}}=0.048$ and $R_{\mathrm{II}, \mathrm{III}}=0.059$ where e.g.

$$
R_{\mathrm{I}, \mathrm{II}}=\Sigma\left[\left|\mathrm{I}_{\mathrm{I}}^{\frac{1}{2}}-\mathrm{I}_{\mathrm{II}}^{\frac{1}{2}}\right|\right] / \frac{1}{2} \Sigma\left[\left|\mathrm{I}_{\mathrm{I}}^{\frac{1}{3}}+\mathrm{IIII}_{\mathrm{II}}^{\frac{1}{2}}\right|\right]
$$

with $I_{i}^{\frac{1}{3}}$ being the square root of the intensity as obtained from the ith measurement. $\Sigma$ denotes the summation over all reflections measured with nonzero intensity. From an analysis of the deviations between the observations of reflections that are in common in the series I, II and III, variances for individual reflections were calculated according to the semi-empirical formula:

$\sigma_{\mathrm{I}}^{2}=\sigma_{c}^{2}+a_{1}+a_{2} \cdot \mathrm{I}^{\frac{1}{2}}+a_{3} \cdot \mathrm{I}+a_{4} \cdot \mathrm{I}^{2}+$ $a_{5} \cdot \sin ^{2} \theta+a_{6} \cdot \sin ^{4} \theta+a_{7} \cdot \mathrm{I}^{\frac{1}{2}} \cdot \sin ^{2} \theta+a_{8} \cdot \mathrm{I} \cdot \sin ^{4} \theta$ $+a_{9} \cdot I^{\frac{1}{2}} \cdot \sin ^{4} \theta+a_{10} \cdot I \cdot \sin ^{2} \theta$ where $\sigma_{c}{ }^{2}$ is the variance as obtained from counting statistics and where the constants $a_{i}$ have the following values: $-43.10^{-2}, \quad-51.10^{-3}, \quad 20.10^{-4}, \quad-20.10^{-9}$, $-17.10^{\circ}, 27.10^{1}, 30.10^{-1}, 57.10^{\circ}, 28.10^{\circ}$ and $72 \cdot 10^{-3}$. (We do not attach a physical meaning to the individual values of these constants.)

For the solution and the refinement of the structure average intensity data were used. From the 1637 symmetry-independent refiections that had been measured above threshold, 50 refiections were excluded from the structure refinement because they showed differences between the three intensity measurements that exceeded $2.5 \sigma$.

\section{Physical measurements}

${ }^{1} \mathrm{H}$ NMR spectra of $\mathrm{Au}(\mathrm{dtc})(\mathrm{mnt})$ were recorded at various temperatures ranging from $20^{\circ} \mathrm{C}$ to $-60^{\circ} \mathrm{C}$, in $\mathrm{CDCl}_{3}$ solution using a Varian HA-100 spectrometer operating at $100 \mathrm{MHz}$.

UV-spectra were measured in methylene chloride solutions using a Unicam SP 700C spectrophotometer.

\section{Structure determination and refinement}

The positions of the gold and sulfur atoms were determined from a three-dimensional Pattersonsynthesis. Three cycles of full-matrix least-squares refinement of the positional parameters and isotropic temperature factors of these atoms resulted in a conventional $R$-factor of 0.135 . From a gold and sulfur atom phased Fourier-synthesir all remaining non-hydrogen atoms were found. Ludstsquares refinement of all non-hydrogen atoms with anisotropic temperature factors reduced $R$ to 0.050 . A difference-Fourier-synthesis computed at this stage (using only terms for which $\sin \theta / \lambda<0.30 \AA^{-1}$ ) showed significant residual electron density $(0.3$ to $0.6 \mathrm{e} \AA^{-3}$ ) in the neighbourhood of the carbon atoms of the butyl chains. Since the differencesynthesis did not allow accurate location of the hydrogen atoms, they were placed at calculated positions in such a way that the best fit with the difference-synthesis was obtained. Several more cycles of full-matrix least-squares refinement with fixed hydrogen parameters reduced $R$ to a final value of 0.047 . (According to Hamilton's test, ${ }^{15}$ the improvement of the model after addition of the hydrogen atoms is highly significant). In the last refinement cycle (using 1587 reflections), changes in parameters did not exceed 0.2 e.s.d. The atomic scattering factors used in the leastsquares refinement were those of $\mathrm{Au}^{+}, \mathrm{S},{ }^{,} \mathrm{C}$ and $\mathrm{H}$. The $\mathrm{Au}^{+}$and $\mathrm{S}$ scattering curves were corrected for the anomalous scattering term $\Delta f^{\prime}$. All pertinent data were taken from the International Tables for X-ray Crystallography. ${ }^{6}$

\section{RESULTS AND DISCUSSION}

\section{Crystal Structure of $A u(d t c)(m n t)$}

The atomic parameters are given in Tables I and II. Bond distances and angles are presented in Figure 1. Projections of the structure along the $b$ and $c$ axes are given in Figures 2 and 3.

As is clearly shown in Figure 3, the structure consists of distinct layers of molecules perpendicular to the $b$-axis. Neighbouring layers are separated by van der Waals distances. Figure 2 illustrates the 
pairwise packing of the molecules around inversion centres, within such layers. The shortest sulfursulfur contacts between one molecule and its neighbours are also shown in Figure 2 and tabulated in Table III. At least one of these contacts is short as compared with the normal S-S van der Waals distance of $3.70 \AA$, however, not so short that the $\mathrm{Au}(\mathrm{dtc})(\mathrm{mnt})$ structure can be interpreted as a clear case of 'inter-donor atom bonding'. ${ }^{12,13}$ Nevertheless the $\mathrm{Au}(\mathrm{dtc})(\mathrm{mnt})$ structure is interesting in view of this suggestion.

Within one molecule, the gold atom is in approximately square-planar coordination, however, the deviations from $\mathrm{mm} 2\left(\mathrm{C}_{2 v}\right)$ symmetry are consic $\iota$ ble. The interligand $\mathrm{S}-\mathrm{Au}-\mathrm{S}$ angles differ by $4.1^{\circ}\left(95.0^{\circ}\right.$ and $\left.99.1^{\circ}\right)$ and the central part of the molecule deviates significantly from planarity. The dihedral angle between the weighted least-squares planes through the atoms of the dtc-ligand and the atoms of the mnt-ligand is $8.5^{\circ}$. Moreover, the gold atom is neither situated in one of these planes nor in the plane through the four sulfur atoms, but at distances of $0.084 \AA, 0.102 \AA$ and $0.035 \AA$ from these planes.

Bond distances and angles within the dtc and mnt ligand of $\mathrm{Au}(\mathrm{dtc})(\mathrm{mnt})$ are essentially the same as those found in bis-(dtc) and bis-(mnt) complexes of gold. 1,8,9,10 Some important dimensions of the 1,1-dithiolato cationic complex $\mathrm{Au}\left(\mathrm{dtc}_{2}{ }_{2}{ }^{+}\right.$, the 1,2-dithiolato anionic complex $\mathrm{Au}(\mathrm{mnt})_{2}{ }^{-}$and the neutral 1,1-dithiolato-1,2-dithiolato complex $\mathrm{Au}(\mathrm{dtc})(\mathrm{mnt})$, are tabulated in Table IV. In view of the discussions about metal-sulfur $\pi$-bonding in 1,1- and 1,2-dithiolato complexes of transition

TABLE I

Final atomic parameters (with e.s.d.) for $\mathrm{Au}(\mathrm{dtc})(\mathrm{mnt})$

The estimated standard deviations are those obtained from the least squares refinement. The expression used for the anisotropic temperature factor is: $\exp -\left(\beta_{11} \mathrm{~h}^{2}+\beta_{22} \mathrm{k}^{2}+\beta_{33} \mathrm{l}^{2}+2 \beta_{12} \mathrm{hk}+2 \beta_{13} \mathrm{hl}+2 \beta_{23} \mathrm{kl}\right)$

\begin{tabular}{|c|c|c|c|c|c|c|c|c|c|}
\hline ATOM & $\mathbf{x}$ & $\mathbf{Y}$ & 2 & $P_{11}$ & $p_{22}$ & $\beta_{33}$ & $\beta_{12}$ & $\beta_{13}$ & $\gamma_{23}$ \\
\hline Au & $0.11650(4)$ & $0.00400(2)$ & $0.20826(6)$ & $0.00502(3)$ & $0.00074(1)$ & $0.1097(8)$ & $0.00011(2)$ & $-0.00012(5)$ & $-0.00028<3$ \\
\hline $\mathrm{s}(1)$ & $0.2489(3)$ & $0.0381(2)$ & $0.1019(5)$ & $0.0063(2)$ & $0.0013(1)$ & $0.0150(7)$ & $-0.0001(1)$ & $0.0014(4)$ & $-0.0013(2)$ \\
\hline$s(2)$ & $0.1575(3)$ & $0.0643(1)$ & $0.3637(5)$ & $0.0070(3)$ & $0.0009(1)$ & $0.0132(7)$ & $-0.0001(1)$ & $0.0011(4)$ & $-0.0003(2)$ \\
\hline$s(3)$ & $0.0956(3)$ & $-0.0494(1)$ & $0.0284(5)$ & $0.0060(3)$ & $0.0012(1)$ & $0.0144(7)$ & $-0.0001(1)$ & $0.0012(3)$ & $-0.0011(2)$ \\
\hline$S(4)$ & $-0.0159(3)$ & $-0.0228(2)$ & $0.3291(4)$ & $0.0071(3)$ & $0.0016(1)$ & $0.0132(7)$ & $-0.0007(1)$ & $0.0013(3)$ & $-0.001 \in(2)$ \\
\hline$N(1)$ & $0.302(1)$ & $0.114(1)$ & $0.251(2)$ & $0.005(1)$ & $0.001(1)$ & $0.016(3)$ & $0.000(1)$ & $-0.001(1)$ & $0.001(1)$ \\
\hline$N(2)$ & $-0.060(1)$ & $-0.143(1)$ & $-0.083(2)$ & $0.011(1)$ & $0.001(1)$ & $0.015(3)$ & $-0.001(1)$ & $-0.001(1)$ & $-0.001(1)$ \\
\hline . 1) & $-0.205(1)$ & $-0.109(1)$ & $0.278(2)$ & $0.011(1)$ & $0.004(1)$ & $0.017(3)$ & $-0.003(1)$ & $0.002(2)$ & $-0.002(1)$ \\
\hline$c(1)$ & $0.245(1)$ & $0.077(1)$ & $0.245(2)$ & $0.006(1)$ & $0.001(1)$ & $0.013(3)$ & $0.000(1)$ & $-0.003(1)$ & $-0.000(1)$ \\
\hline$c(2)$ & $0.380(1)$ & $0.120(1)$ & $0.142(2)$ & $0.006(1)$ & $0.002(1)$ & $0.019(3)$ & $-0.000(1)$ & $0.002(2)$ & $0.001(1)$ \\
\hline$c(3)$ & $0.355(1)$ & $0.155(1)$ & $0.024(2)$ & $0.010(2)$ & $0.002(1)$ & $0.015(3)$ & $0.000(1)$ & $0.001(2)$ & $0.001(1)$ \\
\hline$c(4)$ & $0.430(1)$ & $0.157(1)$ & $-0.088(3)$ & $0.011(2)$ & $0.002(1)$ & $0.026(5)$ & $-0.001(1)$ & $0.008(2)$ & $0.000(1)$ \\
\hline$c(5)$ & $0.412(2)$ & $0.199(1)$ & $-0.205(3)$ & $0.014(2)$ & $0.005(1)$ & $0.025(4)$ & $-0.001(1)$ & $0.009(3)$ & $0.003(2)$ \\
\hline$c(6)$ & $0.292(1)$ & $0.147(1)$ & $0.373(2)$ & $0.007(1)$ & $0.001(1)$ & $0.010(2)$ & $0.000(1)$ & $-0.001(1)$ & $-0.001(1)$ \\
\hline$c(7)$ & $0.221(1)$ & $0.185(1)$ & $0.334(2)$ & $0.008(1)$ & 0.001 & 0.0 & 0.001 & $-0.003(2)$ & $-0.001(1)$ \\
\hline$c(8)$ & $0.204(2)$ & $0.217(1)$ & $0.465(2)$ & $0.013(2)$ & $0.002(1)$ & $0.019(4)$ & $0.001(1)$ & $-0.003(2)$ & $-0.002(1)$ \\
\hline$c(9)$ & $0.134(2)$ & $0.253(1)$ & $0.428(3)$ & $0.017(3)$ & $0.002(1)$ & $0.032(6)$ & $0: 003(1)$ & $-0.003(3)$ & $-0.004(1)$ \\
\hline$c(10)$ & $-0.007(1)$ & $-0.075(1)$ & $0.086(2)$ & $0.006(1)$ & $0.001(1)$ & $0.009(2)$ & $-0.000(1)$ & $-0.000(1)$ & $-0.001(1)$ \\
\hline$c(11)$ & $-0.055(1)$ & $-0.064(1)$ & $0.210(2)$ & $0.006(1)$ & $0.001(1)$ & $0.012(2)$ & $-0.001(1)$ & $0.000(2)$ & $-0.000(1)$ \\
\hline$c(12)$ & $-0.040(1)$ & $-0.114(1)$ & $-0.004(2)$ & $0.007(1)$ & $0.001(1)$ & $0.010(3)$ & $-0.000(1)$ & $0.002(2)$ & $0.000(1)$ \\
\hline$G(13)$ & $-0.138(1)$ & $-0.089(1)$ & $0.248(2)$ & $0.008(1)$ & $0.002(1)$ & $0.012(3)$ & $-0.001(1)$ & $0.002(1)$ & $-0.001(1)$ \\
\hline
\end{tabular}




\section{TABLE II}

Hydrogen parameters

Unrefined results (see text). The first index of the numbering identifies the parent carbon atom. The isotropic temperature factors are the same as those of the parent carbon atom.

\begin{tabular}{|c|c|c|c|c|}
\hline$\Delta$ tom & $x$ & $J$ & $\mathbf{z}$ & $B\left(R^{2}\right)$ \\
\hline$H(2 I)$ & 0.39 & 0.08 & 0.09 & 5.5 \\
\hline $\mathrm{H}(22)$ & 0.45 & 0.13 & 0.19 & 5.5 \\
\hline $\mathrm{H}(3 \mathrm{I})$ & 0.35 & 0.19 & 0.08 & 5.8 \\
\hline $\mathrm{H}(32)$ & 0.29 & 0.15 & -0.03 & 5.8 \\
\hline$H(4 I)$ & 0.50 & 0.17 & -0.04 & 8.0 \\
\hline $\mathrm{H}(42)$ & 0.44 & 0.12 & -0.14 & 8.0 \\
\hline$H(51)$ & 0.46 & 0.19 & -0.29 & 10.0 \\
\hline $\mathrm{H}(52)$ & 0.41 & 0.23 & -0.16 & 10.0 \\
\hline $\mathrm{H}(53)$ & 0.34 & 0.19 & -0.25 & 10.0 \\
\hline$H(61)$ & 0.36 & 0.61 & 0.40 & 4.5 \\
\hline $\mathrm{H}(62)$ & 0.27 & 0.13 & 0.47 & $4 \cdot 5$ \\
\hline $\mathrm{H}(71)$ & 0.25 & 0.21 & 0.24 & 5.9 \\
\hline $\mathrm{H}(72)$ & 0.15 & 0.17 & 0.29 & 5.9 \\
\hline $\mathrm{H}(81)$ & 0.27 & 0.23 & 0.50 & 7.0 \\
\hline$H(82)$ & 0.18 & 0.19 & 0.56 & 7.0 \\
\hline$H(9.1)$ & 0.13 & 0.28 & 0.50 & 10.0 \\
\hline $\mathrm{H}(92)$ & 0.15 & 0.27 & 0.32 & 10.0 \\
\hline HI (93) & 0.06 & 0.23 & 0.41 & 10.0 \\
\hline
\end{tabular}

TABLE III

Intermolecular sulfur-sulfur contacts in Au(dtc)(mnt)

\begin{tabular}{|c|c|c|}
\hline $\begin{array}{c}\text { Contact } \\
\text { (see Fig. 2) }\end{array}$ & Distance $(\AA)$ & Remarks \\
\hline 1 & $3.438(6)$ & distances between \\
\hline 2 & $3.658(6)$ & $\begin{array}{l}\text { members of one pair } \\
\text { (see text) }\end{array}$ \\
\hline 3 & $3.804(6)$ & distances between \\
\hline 4 & $3.814(6)$ & members of different \\
\hline \multirow[t]{2}{*}{5} & $3.915(6)$ & pairs (see text) \\
\hline & 3.70 & van der Waals contact \\
\hline
\end{tabular}

metals, it is interesting to compare the gold-sulfur bond distance in the 1,1-dithiolato unit $\mathrm{Au}(\mathrm{dtc})_{2}{ }^{+}$ with that in the 1,2-dithiolato unit $\mathrm{Au}(\mathrm{mnt})_{2}{ }^{-}$. In $\mathrm{Au}(\mathrm{dtc})_{2}{ }^{+}$this bond length averages $2.333 \AA$, whereas in $\mathrm{Au}(\mathrm{mnt})_{2}-$ it is $2.309 \AA$, yielding a difference of $0.024(7) \AA$. It is significant that a similar difference occurs in the Au(dtc)(mnt) complex, in which the 1,1- and 1,2-dithiolato ligand appear jointly and coordinated with the same gold atom. The Au-S distance in the dtc-moiety of this complex is $2.327 \AA$. whereas in the mnt-moiety it is $2.294 \AA$, so yielding a difference of $0.033(7) \AA$. Differences between 1,1- and 1,2-dithiolato complexes similar to those reported above for gold, have also been observed for other transition metals (e.g. $\mathrm{Ni}^{11}$ ).

Discussions concerning those differences in bond lengths are usually given in terms of the extent of metal-ligand pi-bonding. It has appeared ${ }^{11}$ from several chemical, physical and $\mathrm{X}$-ray investigations that as well in 1,1- as in 1,2-dithiolates in addition to metal-sulfur sigma-bonding, metal-sulfur pibonding may occur. The length of the metal- - ur bond has been considered to be indicative of the extent of metal-ligand pi-bonding. From this point of view it is concluded, ${ }^{11}$ from the observed differences in metal-sulfur bond distances that metal-sulfur pi-bonding in dithiocarbamato $(1,1-$ dithiolato) complexes is considerably less important than it is in maleonitriledithiolato (1,2-dithiolato) complexes. However, this explanation of the differences in metal-sulfur bond lengths between 1,1and 1,2-dithiolates is questionable. In our opinion, it could be explained as well from steric effects. In dithiocarbamato complexes the intra-ligand S-S distance is typically about $2.80 \AA$, whereas in the maleonitriledithiolato complexes this distance averages $3.05 \AA$ in complexes of $\mathrm{Ni}$ and $\mathrm{Cu}$, and $3.25 \AA$ in complexes of $\mathrm{Au}$. In the gold complexes the intra-ligand $\mathrm{S}-\mathrm{Au}-\mathrm{S}$ angle is about $75^{\circ}$ for dithiocarbamates anda bout $90^{\circ}$ for maleonitriledithiolates. These differences in $\mathbf{S}-\mathbf{A u}-\mathbf{S}$ bond angles and in intra-ligand $\mathbf{S}-\mathbf{S}$ distances betwreen the 1,1- and the 1,2-dithiolato systems migl je reflective of the efficiency of the sigma overlap between the gold and sulfur atoms. Therefore the observed differences in metal-sulfur bond lengths between 1,1- and 1,2-dithiolates, in our opinion, are not such clear cut indicators for differences in metal-sulfur pi-bonding as is sometimes suggested.

Some differences in bond lengths of chemically equivalent bonds in the $\mathrm{Au}(\mathrm{dtc})(\mathrm{mnt})$ molecule (e.g. $C(1)-S(1)$ and $C(1)-S(2)$ ), are not significant and therefore do not justify the conclusion that the individual ligands are asymmetrically coordinated to the gold atom.

\section{Spectra}

As mentioned above, the interligand $\mathrm{S}-\mathrm{Au}-\mathrm{S}$ angles differ by $4.1^{\circ}$. To investigate whether this irregular coordination of the gold atom by the dtc and mnt 
ligand in $\mathrm{Au}(\mathrm{dtc})(\mathrm{mnt})$ is caused by intermolecular forces peculiar to the crystalline state, or whether it also exists in solution, ${ }^{1} \mathrm{H}$ NMR spectra of the complex were recorded at various temperatures. No splitting of the $N$-alkyl proton resonances could be observed at temperatures as low as $-60^{\circ} \mathrm{C}$. From this result no definitive conclusion is possible, however, since the absence of splitting might also be due to an undetectably small difference in the magnetic environments of the $\mathrm{N}$-alkyl groups. ${ }^{14}$

The ultraviolet spectrum of $\mathrm{Au}(\mathrm{dtc})(\mathrm{mnt})$ is clearly different from that of the isomeric complex $\mathrm{Au}(\mathrm{dtc})_{2}{ }^{+} \mathrm{Au}(\mathrm{mnt})_{2}{ }^{-}$(Table V). The structure of the last compound in the solid state was proved to consist of two gold(III)-containing complex ions, $\mathrm{Au}(\mathrm{dtc})_{2}{ }^{+}$and $\mathrm{Au}(\mathrm{mnt})_{2}-{ }^{1}$ The spectral data show that the spectrum of this compound is best described as the sum-spectrum of the spectra of the compounds $\mathrm{Au}(\mathrm{dtc})_{2} \mathrm{Br}$ and $\left(\mathrm{C}_{4} \mathrm{H}_{9}\right)_{4} \mathrm{~N} \mathrm{Au}(\mathrm{mnt})_{2}$. This demonstrates that in solution the $\mathrm{Au}(\mathrm{dtc})_{2}{ }^{+} \mathrm{Au}(\mathrm{mnt})_{2}{ }^{-}$-complex is still ionic and shows no rearrangement reaction to $\mathrm{Au}(\mathrm{dtc})(\mathrm{mnt})$. Such a rearrangement reaction is shown by the $\mathrm{Au}(\mathrm{dtc})_{2}{ }^{+} \mathrm{AuBr}_{4}-$ complex, that in solution rearranges to $\mathrm{Br}_{2} \mathrm{Au}(\mathrm{dtc}){ }^{9}$ Thus, the different stereochemical patterns found in the solid state for both the isomers with stoichiometric formula $\mathrm{Au}(\mathrm{dtc})(\mathrm{mnt})$, are retained in solution.
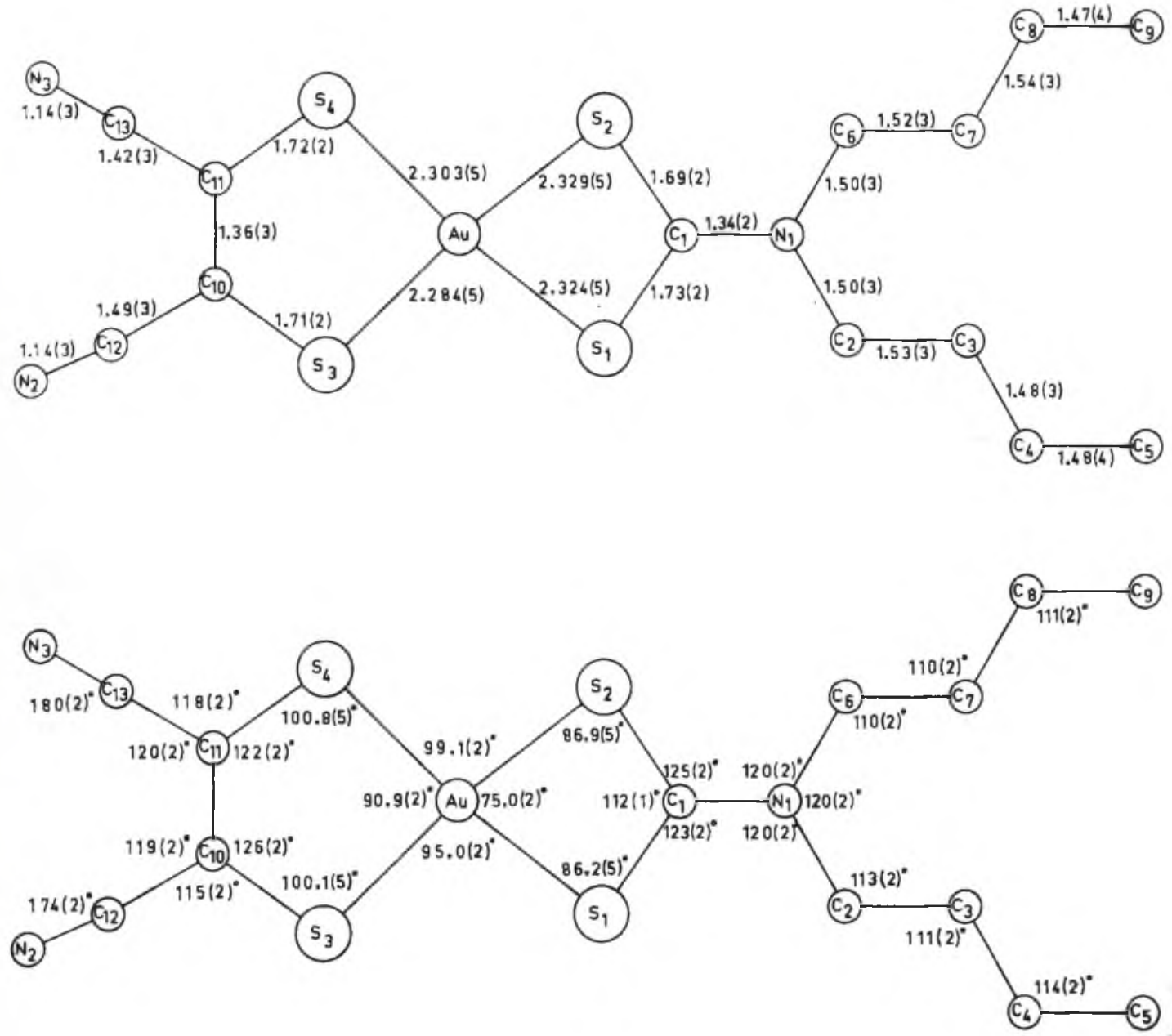

FIGURE 1 Dimensions of $\mathrm{Au}(\mathrm{dtc})(\mathrm{mnt})$, with estimated standard deviations 


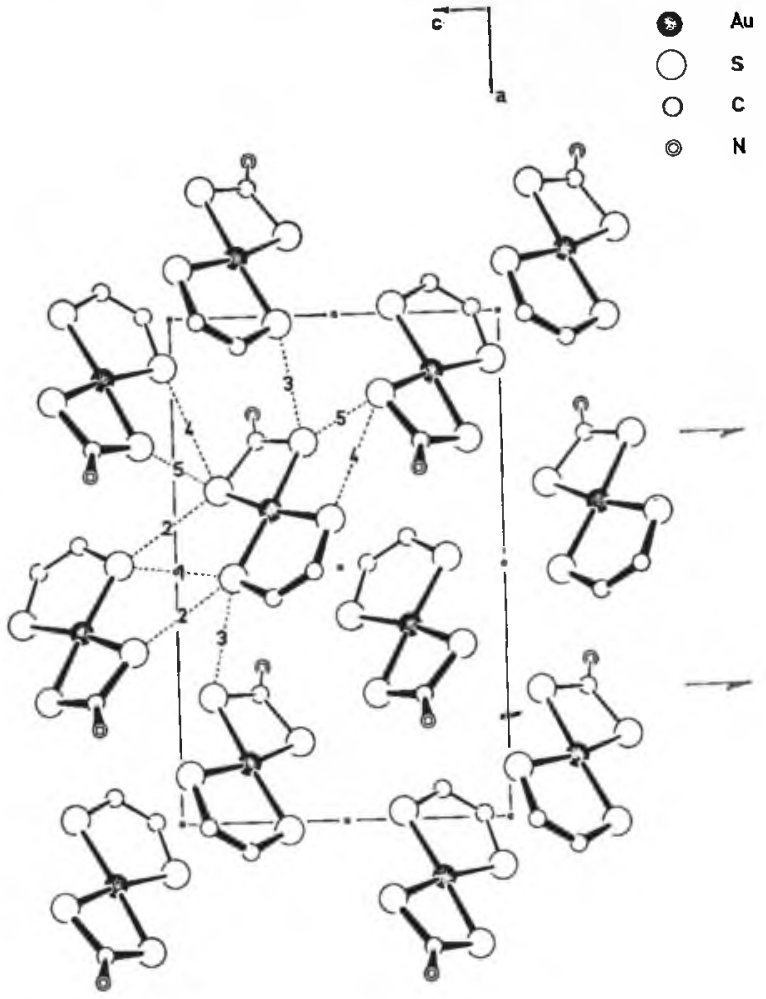

FIGURE 2 Projection of the structure of $\mathrm{Au}(\mathrm{dtc})(\mathrm{mnt})$ along the $b$-axis. Butyl chains and $\mathrm{CN}$ groups are omitted.

TABLE IV

Bond distances and angles in $\mathrm{Au}(\mathrm{dtc})_{2}+, \mathrm{Au}(\mathrm{mnt})_{2}-$ and $\mathrm{Au}(\mathrm{dtc})(\mathrm{mnt})$

\begin{tabular}{|c|c|c|c|c|c|c|}
\hline \multirow[t]{2}{*}{ Complex } & \multicolumn{3}{|c|}{ Distances $(\AA)$} & \multicolumn{3}{|c|}{ Angles $\left({ }^{\circ}\right)$} \\
\hline & $\mathrm{Au}-\mathrm{S}$ & $\mathbf{S}-\mathbf{C}$ & $\mathrm{C}-\mathrm{N} / \mathrm{C}-\mathrm{C}^{b}$ & $\mathbf{S}-\mathbf{A u}-\mathbf{S}$ & $A u-S-C$ & S-C-S/S-C-C \\
\hline $\mathrm{Au}(\mathrm{dtc})_{2}+a$ & $2.333(7)$ & $1.76(3)$ & $1.30(3)$ & $75.1(2)$ & $87.8(6)$ & 109... \\
\hline $\mathrm{Au}(\mathrm{mnt})_{2}-$ & $2.309(4)$ & $1.75(2)$ & $1.35(2)$ & $90.7(2)$ & $101.1(6)$ & $123.0(10)$ \\
\hline dtc-lig. & $2.327(5)$ & $1.71(2)$ & $1.34(2)$ & $75.0(2)$ & $86.5(5)$ & $112.0(10)$ \\
\hline \multicolumn{7}{|l|}{$\mathrm{Au}(\mathrm{dtc})(\mathrm{mnt})$} \\
\hline mnt-lig. & $2.294(5)$ & $1.71(2)$ & $1.36(2)$ & $90.9(2)$ & $100.5(5)$ & $124.0(20)$ \\
\hline
\end{tabular}

All values are averages of symmetry-independent values.

average values from references $1,8,9$ and 10 .

${ }^{b} \mathrm{C}-\mathrm{N}$ distance and $\mathrm{S}-\mathrm{C}-\mathrm{S}$ angle in dtc, and $\mathrm{C}-\mathrm{C}$ distance and $\mathrm{S}-\mathrm{C}-\mathrm{C}$ angle in mnt.

TABLE V

Electronic Spectra of Golddithiolato complexes in $\mathrm{CH}_{2} \mathrm{Cl}_{2}$ solutions

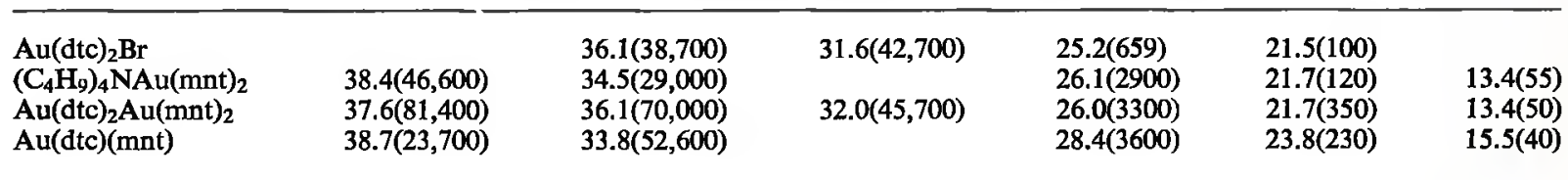

Band maxima in kK: parentheses indicate $\epsilon\left(\mathrm{lmole}^{-1} \mathrm{~cm}^{-1}\right)$. 


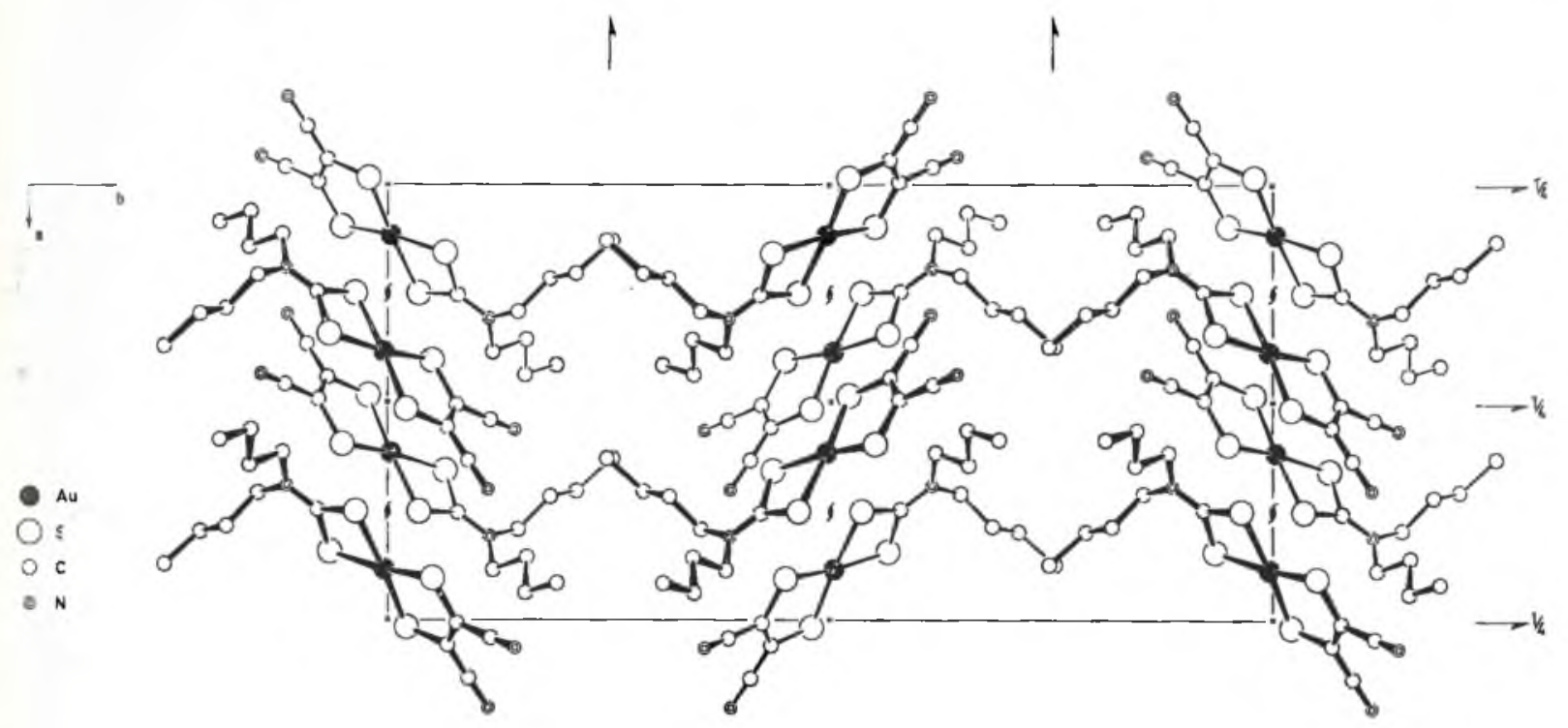

FIGURE 3 Projection of the structure of $A u(d t c)(m n t)$ along the $c$-axis

\section{ACKNOWLEDGEMENTS}

The authors wish to thank Dr. P. T. Beurskens for his co-operation in the structure analysis, and Prof. Dr. Ir. J. J. Steggerda for his interest in this work.

\section{REFERENCES AND NOTES}

1. J. H. Noordik and P. T. Beurskens, J. Cryst. Mol. Structure 1, 339 (1971).

2. J. G. M. van der Linden, J. Inorg. Nucl. Chem., in the press.

3. J. G. M. van der Linden and H. G. J. van de Roer, r rg. Chim. Acta 5, 254 (1971).

4. ently the crystal structure determination of a mixedligand tris-complex, $\mathrm{Fe}\left(\mathrm{S}_{2} \mathrm{CNet}_{2}\right)_{2}\left(\mathrm{~S}_{2} \mathrm{C}_{2}\left(\mathrm{CF}_{3}\right)_{2}\right)$ has been reported. D. L. Johnstone, W. L. Rohrbaugh and W. Dew. Horrocks, Inorg. Chem. 10, 1474 (1971).

5. W. R. Busing and H. A. Levy, Acta Cryst. 10, 180 (1957).
6. International Tables for X-ray Crystallography, Vol. III, The Kynoch Press, Birmingham, 1962.

7. The weights used in the least-squares calculation of mean planes through groups of atoms are based upon the accuracy of the positional parameters.

8. P. T. Beurskens, H. J. A. Blaauw, J. A. Cras and J. J. Steggerda, Inorg. Chem. 7, 805 (1968).

9. P. T. Beurskens, J. A. Cras and J. G. M. van der Linden, Inorg. Chem. 9, 475 (1970).

10. J. A. Cras, J. H. Noordik, P. T. Beurskens and A. M. Verhoeven, J. Cryst. Mol. Structure 1, 155 (1971).

11. R. Eisenberg, Progress Inorg. Chem. Vol. 12, 295 (1971).

12. R. Eisenberg, E. 1. Stiefel, R. C. Rosenberg and H. B. Gray, J. Am. Chem. Soc. 88, 2874 (1966).

13. E. I. Stiefel, Z. Dori and H. B. Gray, J. Am. Chem. Soc. 89, 3353 (1967).

14. H. C. Brinkhoff and A. M. Grotens, Rec. Trav. Chim. 90, 252 (1971).

15. W. C. Hamilton, Acta Cryst. 18, 502 (1965). 